\title{
Adolpho Mello - De seu Manual: "Pequena Arte da Expressão do Violino" e Considerações sobre a Música de Salão em Desterro e São José
}

\author{
Adolpho Mello's Handbook: \\ 'Small Art of Expression of the Violin' and considerations \\ about Salon Music in Desterro and São José
}

por Flora Ferreira Holderbaum

\begin{abstract}
RESUMO
Este trabalho tem como foco a obra teórico-técnica intitulada "Pequena Arte da Expressão do Violino ou Nuanças que fazem a Beleza da Execução", de Adolpho Ferreira de Mello, compositor, intérprete e maestro natural de São José (SC) que atuou naquela cidade e em Desterro* (atual Florianópolis), nos fins do século XIX e início do XX. Traçaremos um breve perfil histórico das duas cidades vizinhas, situando o contexto musical local frente ao cenário nacional da Música de Salão e, através de artigos em revistas e jornais da época, resgataremos informações sobre a atuação musical de Adolpho Mello, a fim de lançar um olhar mais amplo sobre sua figura histórica. A seguir, faremos uma análise de seu manual de violino, analisando os conceitos ali apresentados à luz da literatura pedagógica do violino. Verificaremos assim, a relação entre a obra pesquisada e o referencial teórico-tecnico violinístico encontrado em Galamian e Flesch.
\end{abstract}

Palavras-chave Adolpho Mello; Violino; Música de Salão; Desterro; São José

\section{ABSTRACT}

This article analyzes the theoretical-technical publication entitled "Pequena Arte da Expressão do Violino ou Nuanças que fazem a Beleza da Execução", by Adolho Mello, composer, interpreter and conductor born in São José (SC), who acted in his hometown and in Desterro (today's Florianópolis), by the end of the 19th century and early 2oth century. We will trace a brief historical profile of the two neighbor cities, situating its musical context in the national scenario of Música de Salão and, through the research of articles in magazines and newspapers from Adolpho Mello's time, we will collect information about his musical acting in order to have a wider perspective on this historical figure. After that, we will assess his manual about the violin, analyzing the concepts therein in light of the violin's pedagogical literature. Thus we will verify the relation between the researched literature with the violin's theoretical-technical references found in Galamian and Flesch.

Keywords Adolpho Mello; Violin; Salon Music; Desterro; São José 


\section{Introdução}

Adolpho Ferreira de Mello nasceu em São José, Santa Catarina, em 20 de outubro de 1861 e faleceu em Florianópolis a 1ć de novembro de 1926. Além de violinista, compositor e regente, atuou em cargos públicos, tendo sido Tesoureiro-Geral do estado e diretor do conselho Municipal de Desterro. Deixou vasto material musical escrito (de posse da família Mello na atualidade), assim como variadas obras para violino, além de um volume com orientações teóricas, técnicas e estéticas, chamado "Pequena Arte Da Expressão do Violino ou Nuanças que fazem a Beleza da Execução" (MELLO, 2003). 0 Teatro Municipal de São José leva seu nome.

0 ambiente musical da época se mostra, através da bibliografia consultada, ativo e atualizado em relação aos principais centros urbanos do país, especialmente no tocante à 'Música de Salão' praticada nos lares das famílias mais abastadas, uma elite composta por famílias ligadas ao sistema rural colonial e que agora tratava de europeizar ou "afrancesar" o modelo social, a moda, os costumes e os artigos de status social (como o piano), para manter seu prestígio.

Através de partituras cedidas pela família de Adolpho Mello entramos em contato com sua obra para violino e piano. Suas composições apresentam diversos aspectos técnico-interpretativos que remetem a um tipo de virtuosidade e brilhantismo característico do repertório de salão².

$\mathrm{Na}$ coleta de dados em jornais da época e revistas locais, verificamos sua participação em variados concertos solo, na direção de orquestras e em palestras sobre temas musicais.

Deixou, além de peças para violino e piano, um manual teórico-técnico intitulado: "Pequena Arte da Expressão do Violino ou Nuanças que fazem a Beleza da Execução". A partir da análise desta obra, identificaremos os fundamentos que Mello expõe como resultado de sua própria pesquisa instrumental, bem como a similaridade que esses fundamentos têm com a literatura pedagógica do violino. Adolpho Mello cita Charles Auguste de Beriot, Niccolò Paganini, Hubért Léonard, Delphin Allard e Giovanni. Battista Viotti; além dos didatas mencionados, é também nas obras pedagógicas de Carl Flesch e Ivan Galamian que encontraremos aspectos técnicos suscitados por A. Mello em seu manual. Tais aspectos - como sonoridade, técnica de mão direita, tipos de golpes de arco, efeitos - podem ser encontrados em trechos específicos que ilustram seu ponto de vista teórico-interpretativo.

1 A França era o modelo universal de civilidade no século XIX.

2 Essas obras serão objeto de estudo em etapas posteriores desta pesquisa. 


\section{Contexto histórico}

Os Ferreira de Mello aparecem, junto com as famílias Vieira da Rosa, Xavier Neves, entre outras, como algumas das famílias mais influentes do período. Na segunda metade do século XIX, mais precisamente em 1883, São José se erguia de freguesia à vila e celebrava festas solenes nas Igrejas e sobrados:

(...) Este acontecimento importantíssimo foi recebido com muita festa: um solene Te Deum foi cantado em ação de graças na Igreja matriz; muitas diversões populares e suntuosos saraus aconteceram nos principais sobrados do novo município. À noite, os frontispícios destes sobrados foram iluminados a azeite, na transparência de vidros coloridos. Eram os sobrados pertencentes a João Vieira da Rosa _ então Presidente da nova Câmara_ (sobrado este já demolido, situado na parte inferior da Praça); o solar pertencente ao Coronel Joaquim Xavier Neves (situado na atual Rua Gaspar Neves, hoje propriedade da Sra. Emília Maciel Rosa); o sobrado do Coronel Luis Ferreira do Nascimento Mello (situado na esquina da Gaspar Neves com a Praça Arnoldo Souza, recentemente decretado de utilidade pública pela Prefeitura Municipal); o sobrado pertencente ao comerciante português José Antônio de Pinho _ (hoje da família Gerlach) (...). Luis Ferreira de Mello foi também quem lançou a pedra fundamental do $7^{\circ}$ Teatro de São José. Começaram em 17 de setembro de 1854 e viriam a ser concluídas no dia 21 de Junho de 1856. (GERLACH; MACHADO, 1982, s/p.)

Com relação ao ambiente político sócio-econômico de São José, pode-se dizer que:

(São José) era um dos municípios mais populosos e ricos da Província de Santa Catarina. Exportava café, tapioca, açúcar, lenha em achas, farinha de mandioca, cachaça e algodão,(...) dispunha de porto marítimo apreciável, freqüentado por grande número de embarcações(...). o comércio progredia consideravelmente e os partidos políticos que disputavam os mandatos exerciam a chefia sobre os importadores e exportadores, (...). (GERLACH; MACHADO, 1082, s/p.)

Desterro, cidade-ilha vizinha, vinha afirmando sua economia, delineando seu perfil social e exercendo também sua interação política e cultural:

Em meados do século XIX a cidade de Desterro passou por algumas transformações significativas. A década de 1850 foi favorável à exportação de gêneros alimentícios, enriquecendo os proprietários de terras mais abastados e os comerciantes de Desterro que exportavam alimentos. É a época em que começam a ser edificados na cidade os sobrados, signo da elite ascendente. Ao mesmo tempo que foi um período de prosperidade, os jornais da cidade comentavam que os gêneros de primeira necessidade subiam a um "preço espantoso". (GERLACH; MACHADO, 1982, s/p.) 
Adolpho Mello se consagra em um período no qual a música cumpria um papel social em favor de uma aristocracia emergente, cujas raízes estavam plantadas no colonialismo e o senhorio feudal e rural junto ao sistema escravagista, e que, naquele momento, procurava adequar-se aos novos padrões de civilidade burguesa, cujo modelo era principalmente a sociedade francesa do Segundo Império (1852-70) (NOVAIS; ALENCASTRO, 1997, p. 44). 0 modus operandi desta classe eram as festas e reuniões nos casarões, sobrados e salões. Esse novo estilo social confere um tom de modernidade e afirma o status das famílias dominantes nas cidades brasileiras.

A europeização da vida social impunha-se às elites brasileiras como condição para a manutenção do seu prestígio. Uma nova sociabilidade_ a das festas particulares, a dos salões do império_será dada à família brasileira, alternando-Ihe profundamente a identidade, determinando-Ihe um novo modelo de organização. (MURICY, 1988, p. 53).

Desterro não foge às descrições deste meio cultural europeizado e afeito aos saIões. Junto às casas e salões encontramos as Sociedades e Clubes Musicais, que desempenharam papel muito importante na cultura e disseminação musical da época. Muitas vezes eram através destas associações que artistas de outras regiões tinham acesso a Desterro e São José.

Os bailes permeavam a vida da cidade por todo o século XIX. Eram patrocinados e organizados por algum membro da sociedade e oferecidos a oficiais estrangeiros a bordo de algum navio importante, a visitantes ilustres como o Imperador e tinham ainda por motivo o dia da Independência, a comemoração da data da visita do Imperador, bem como seu aniversário. Eram realizados no Palácio do Governo, no quartel de Campo Manejo, no prédio do Liceu, ou nos salões dos patrocinadores. (BRAGA, 2000, p 22)

A popularização de danças européias junto a ritmos locais é uma característica da música do período.

As danças mais comuns eram as habaneras, versovianas, scottiches, mazurcas, polonaises e quadrilhas, executadas por orquestras, por piano $e$ violino, ou por orquestra composta de piano, violinos, clarinetes e contrabaixo. (CABRAL apud, BRAGA, 2000, p. 23)

A presença do piano, os salões da aristocracia, as Sociedades e Clubes Musicais, as danças européias misturadas a ritmos locais, a inserção da música nos ambientes privados, a valorização do virtuosismo através da redução de trechos de óperas em Fantasias e Árias, eram características da Música de Salão no Rio de Janeiro e no restante do Brasil. Verificamos repertório semelhante sendo praticado na Desterro do mesmo período:

O repertório consistia geralmente de trechos de óperas dos séculos XVIII e XIX de compositores estrangeiros, principalmente italianos - fantasias, 
árias, cavatinas, souvenirs e variações, seguindo basicamente o mesmo padrão praticado no Rio de Janeiro e São Paulo. (BRAGA, 2000, p 33 -34)

\section{Adolpho Mello em revistas e jornais da época:}

Junto ao acervo de jornais da época, presente na Biblioteca Pública do Estado, encontram-se em torno de 30 citações sobre Adolpho Mello. Sua participação é relatada em palestras sobre música, apresentações solo ou em duetos com piano ou flauta, e conduzindo alguma orquestra, como a Orquestra 12 de Agosto, pertencente o clube de mesmo nome. Segue um artigo citando seu nome, intitulado "Concerto":

Sobre o concerto anterior. A banda da Sociedade Guarany executou o Hino Nacional na abertura. Depois houve discursos. Na parte musical houve a sinfonia La Croix d' Honneur, habilmente executada pela banda da sociedade Guarany. Os Srs. Francisco José da Costa e João A. Ferreira de Mello executaram na flauta e violino, respectivamente, duas fantasias das óperas Norma e Aida e um dueto do Átila, acompanhadas ao piano pelo distinto professor o Sr. José Brasilício de Souza, os quais receberam merecidos aplausos. (O DESPERTADOR, 17 Jul. 1882)

As fontes apresentam Adolpho Mello como exímio violinista, compositor, maestro de orquestras locais, das chamadas Uniões, Sociedades Musicais e Clubes, como o já citado 12 de Agosto. Além disso, Mello aparece fazendo parcerias musicais com José Brasilício Souza, autor do Hino de Santa Catarina, e com outros músicos, como o pianista Francisco João da Costa, também ao piano:

Sobre o concerto no Theatro Santa Isabel. Compareceram neste José Brasilício, Francisco Costa, João Adolpho Ferreira de Mello e a Sociedade Musical Guarany. (A REGENERAÇÃO, 20 Jul, 1882)

Além das composições que listamos ao fim desta seção, retiradas de ROSA (2002), encontramos em jornais da época outras, tais como: "Declarações", "As Moreninhas Desterrenses", polca para piano, (Jornal do Comércio, 24 de janeiro, 1882), e "Uma Flor no Baile", polca para piano (Província, 20 de junho de 1882).

Há uma notícia sobre uma soireé organizada pelo Club 12 de Agosto, na qual foram tocadas entre outras peças, a composição de Adolpho Mello, "Noturno para Violino" (0 Dia, 15 de novembro, 1904).

São relatadas outras aparições de Mello como "sobre o concerto no Theatro Santa Isabel. Compareceram neste José Brasilício, Francisco Costa, João Adolpho Ferreira de Mello e a Sociedade Musical Guarany" (A Regeneração, 20 julho, 1882), bem como anúncios de concertos a serem realizados: "Petit concert" no Club Estrela D’Alva, incluindo adaptações de II Trovatore (piano e violino), A Africana (flauta 
e piano), 0 Pirata (piano e violino) onde tocarão Adolpho Mello, Emilia Schuttel, Francisco Costa, Roberto Trompowsky.(...)"( A Regeneração, 28 de novembro, 1886).

Em uma notícia de um concerto no Club 12 de Agosto, realizado pela soprano Elisa Bassi, de passagem para Europa, são anunciados para o concerto o pianista e maestro Angelo Tagnin e o violinista Adolpho Mello. (0 Dia, 03 de fevereiro,1903) Noutro posterior, se dá a crítica e programa do concerto realizado:

Effectuou-se ante-hontem o festival artístico promovido em seu beneficio pela distincta prima-dona soprano dramatico signora Elisa Bassi. 0 concerto effecutou-se nos luxuosos salões do club Germania, que reuniu numerosa e selecta sociedade. Como em sua primeira festa, a signora Bassi tornou-se merecido alvo dos ruidosos applausos com que foi saudada durante o concerto - applausos que egualmente couberam ao nosso intelligente conterraneo Adolpho Mello e ao signor A. Tagnin. (...) (O Dia, 11 de fevereiro, 1903)

Mello aparece conduzindo um concerto numa notícia sobre a inauguração do Grêmio Violeta ( 0 Dia, 23 de setembro, 1903). Sua presença também é marcada como professor de música, na parte de "Anúncios"- "Música" do Jornal A Província (20 de agosto, 1882):

"Adolpho Ferreira de Mello dá lições de rabeca. (Segue por várias ediç̃os)"; e em nota sobre o início das aulas do estabelecimento "Parthenon Catharinense", trazendo a lista do corpo docente, entre eles "João Adolpho Ferreira de Mello'. ( A República, 27 de fevereiro, 1892)

Laércio Caldeira de Andrada (1890-1971), um dos fundadores da Academia Catarinense de Letras, dedica um texto a Mello no qual traça elogios rasgados ao estilo "mavioso" e arrebatador do violinista; comenta o seu convívio pessoal com o compositor e resume o conteúdo da obra teórica sobre de A. Mello sobre o violino. Relata também algumas de suas aparições na rede social dos clubes e sociedades:

1917:_ Sábado, 10 de novembro_noite, Clube XII. 0 grêmio feminino do Clube promoveu um sarau familiar. (...) Após o hino do Clube é feita uma palestra "A Gênese do Som", e a senhora Antonieta Mello cantou uma cavatina. Adolpho Mello mais uma vez enlevou a assistência interpretando "Melodie" de Rubinstein e "Rapsódia Húngara", de Hauer; e mais "Os Pássaros", fantasia, criação, dele mesmo, inspirada em "Le Canari", de Poliakim. 0 jovem Arthur Freysleben magistralmente acompanhou o grande artista ao piano (ANDRADA, 1955, s/p.)

Muito embora não possamos confirmar sua erudição musical, sua obra teórica e suas composições para violino denotam elevado conhecimento da técnica violinística.

Segue abaixo tabela com a lista de obras de Adolpho Mello, de acordo com o acervo fornecido gentilmente pela família do músico e extraído de Rosa (2002): 


\begin{tabular}{|l|}
\hline \multicolumn{1}{|c|}{ COMPOSIÇÕES PARA VIOLINO (ROSA, 2002) } \\
\hline Primícias (0p. 1) \\
\hline Romance e Mazurca (Op 2) \\
\hline Ária e Trêmulo (Op. 3Fonte: \\
\hline Capricho e Tarantela (0. 4) \\
\hline Serenata (Op. 5) \\
\hline Acalentando- Berceuse (0p. 6) \\
\hline Nostalgia (Op. 7) \\
\hline Ária Variada - Carnaval (Op. 8) 0s Pássaros- Fantasia e Variatio (As duas estão como opus 8) \\
\hline Adágio da Serenata de Beethoven -Au Claire de lune (0p. 9) \\
\hline Reminiscências- Fantasia (op. 10) \\
\hline Tarantella no 2( Op. 11) \\
\hline Souvenir de Verdi -Fantasia (0p. 12) \\
\hline Nas Selvas -Melodia (0p. 13) \\
\hline Meditação - Melodia (0.p 14) \\
\hline Legenda (0p. 15) \\
\hline Rhapsodia (0p. 16) \\
\hline Martha de Flotown -pot-pourrie (0p. 17) \\
\hline $\begin{array}{l}\text { Opus 18,19,20 21= ? (0 arquivo da família alega existir tais opus, porém não encontramos as } \\
\text { partituras) }\end{array}$ \\
\hline
\end{tabular}

\section{Manual à Luz da Literatura Pedagógica do Violino}

Adolpho Mello publicou um livro intitulado: Pequena Arte Da Expressão do Violino ou Nuanças da Beleza da Execução (Mello, 2003), inicialmente lançado pelo chamado Gabinete Tipográfico Sul-Americano, situado na Rua Trajano, em Florianópolis, em 1901. Nele, Mello aborda técnicas e ensinamentos relativos ao violino, conhecimentos que, embora brevemente esboçados, se mostram em sintonia com a literatura pedagógica do violino, através de violinistas didatas renomados como Niccolò Paganini, Giovanni Battista Viotti, e Charles de Bériot.

A fim de melhor situar a obra de A. Mello, faremos uma breve introdução sobre a tradição violínistica na Europa, identificando as escolas técnico-pedagógicas que firmaram presença no contexto musical do violino no século XIX e que constituem as chamadas "escolas de violino"_ formando a linha que enlaça seus predecessores Arcangelo Corelli (1653-1713) e Giuseppe Tartini (1692-1770)_e que no século XIX irá definir uma espécie de "nova" sonoridade ao violino, com Giovanni Battista Viotti (1755-1824) e as escolas Francesa e Franco-Belga. Viotti é tido por excelência, como o grande antecessor de variados violinistas-professores. Segundo Bachmann, 
A lista (de mestres do violino ligados à Viotti) inclui de Beriot, que foi professor de Vieuxtemps; Kreutzer, que ensinou violino à Lafont e também Bazzini; Rode que introduziu Mayseder e Böhm, assim como muitos outros grandes artistas, (...).(BACHMANN, 1966, p 158-159)

A partir de Viotti temos uma série de grandes mestres do violino, que fizeram escola através de seus pupilos. Por "grandes mestres" de uma escola de violino, Bachmann se refere aos "mestres que treinaram pupilos que ficaram famosos, e cujos princípios foram mantidos até hoje."(...).(BACHMAN ,1966 p, 160)

Viotti é o principal predecessor do que vai se tornar a tradição técnica e teórica do violino na Europa. A 'Escola Francesa', com Rode, Baillot e Kreutzer, e a Franco -Belga, com Charles de Bériot, ambas no século XIX, compartilham seus fundamentos. É nesta época que também irá se estabelecer uma construção específica do arco usado hoje, e um novo tipo de som, mais apropriado às grandes salas de concerto, vai derivar desse ajuste, feito por Tourte3, na França, a pedido de Viotti.

Giovanni Battista Viotti é considerado o precursor de uma nova maneira de tocar, depois do classicismo. Foi treinado na tradição Italiana por Pugnani e foi à Paris em 1782. Lá ele inspirou os fundadores da escola Francesa de violino (Baillot, Rode e Kreutzer), os quais exerceram imensa influência na maneira de tocar violino no século XIX. (...) Ele foi um dos primeiros a apreciar as belezas particulares da corda mais grave (G), inclusive em altas posições; $e$ seus concertos unem o estilo cantábile, passagens brilhantes, e arcos muito especializados como o arco "Viotti".(...) Paganini e Baillot estabeleceram o standard técnico do início do século XIX. Uma escola de violino similar a de Paris, foi fundada em Bruxelas, em 1843 por Charles-Auguste de Bériot, quem, como os parisienses, estava em débito com Viotti. Entre os ilustres sucessores de de Bériot estão Hubert Leonard, Henry Vieuxtemps, Henryk Wieniawski e Eugène Ysä̈e;(...)." (STOWEL, tradução nossa)

Mello refere-se à Charles A. de Bériot (1802- 1870), três vezes em seu manual: usa o Concerto Solo $n^{\circ}$ 9, 0p. 104 e cita método deste para explicar uma técnica específica de pontuação (articulação) do arco. "Pequena Arte da Expressão" demonstra um sólido conhecimento dos fundamentos da escola destes chamados mestres, a partir de Viotti. Métodos pedagógicos publicados por de Bériot, como "Méthode de Violon, 0p.102" (1858), e outros mais recentes, contemporâneos de

3 Tourte foi o archetier que, aconselhado por Viotti, redesenhou o arco para o que conhecemos hoje e que "(...) passou a ser adotado como o arco ideal para reprodução da nova sonoridade somente a partir das mudanças estéticas advindas com o romantismo. Sua capacidade de sustentação e de igualdade do som, proporcionadas pelo maior equilíbrio de peso entre 0 talão e a ponta, e pela curvatura convexa do arco, o habilitaram a substituir os arcos antigos, provenientes de vários modelos, utilizados desde o início do séc. XVII. Estes arcos, de fato, eram mais apropriados para o aproveitamento da articulação e da ressonância natural do instrumento, projetando, entretanto, menor volume de som que os arcos modelo Tourte.". (FIAMINGH, 2009, p 17) 
Mello e atuantes na primeira metade do século XX, como Carl Flesch (1873-1944), autor de "Die Kunst des Violinspiels" (1928) são, se não citados diretamente em seu manual, sugeridos indiretamente, como no caso de Flesch. Quanto a este último, o referencial teórico-técnico a ser utilizado aqui é o de sua classificação de "Arcadas" 4, apoiando-nos no livro Arcadas e Golpes de Arco, (SALLES, 1998), que nos apresenta um estudo de classificação e definição dos golpes de arco na técnica violinística de Marcos Salles, Carl Flesch e Ivan Galamian.

Segundo Salles (1998, p. 27) Flesch subdivide as arcadas em quatro grandes famílias, as arcadas longas ${ }^{5}$, as arcadas curtas $^{6}$, as arcadas jogadas e saltadas ${ }^{7}$ e as arcadas mistas. ${ }^{8} .0 \mathrm{~s}$ instrumentos friccionados por arco, como o violino, possuem uma característica peculiar de combinar sons longos com sons curtos. 0 arco gera um tipo de som sem interrupção e contínuo, nas arcadas longas, e desse mecanismo gera-se uma gama rica de tipos de arcadas longas, ou conjunto de golpes de arco com características similares de som contínuo. Aliada a essa capacidade de realizar sons ininterruptos, também há a possibilidade de gerar com o arco sons muito curtos e articulados, usando o arco de forma a "saltar" ou "quicar" sobre as cordas, nas arcadas curtas, nas arcadas saltadas e jogadas, e ainda podemos misturar estas três famílias, nas arcadas mistas.Veremos como Mello chega muito perto destas definições de arcadas de Flesch, em seu "Pequena Arte da Expressão do Violino".

No manual de A Mello encontramos passagens que remetem até mesmo a obras pedagógicas publicadas posteriormente à sua morte, como "The Principles of Violin Playin U Teaching (1962), de Ivan Galamian (1903-1981). Galamian divide seu

4 "Definimos o termo arcada como o ato de ir e vir, a direção do movimento do arco. Pode ser para cima, ou seja, começando o movimento da ponta em direção ao talão (...), ou para baixo, do talão à ponta (...). Será usado também como termo genérico, ou seja, conjunto de determinados golpes de arco agrupados em categorias como, por exemplo, arcadas lisas (longas) ou arcadas curtas."(SALLES, 1998, p 20, grifo nosso)

5 “0 aspecto característico das arcadas longas consiste primeiramente na ausência de interrupções ou pausas entre os golpes e não, como o nome sugere primeiramente, de golpes largos. Três grupos de golpes de arco fazem parte desta primeira família: son filé, legato e detaché (...) (SALLES, 1998, p.27.)

6 "A segunda família, a das arcadas curtas, consiste primeiramente na presença de pausas entre os golpes. Em segundo lugar, nota-se a presença de acentos, por intermédio do aumento de pressão do arco, nas notas e nas pausas. Fazem parte desta família dois grupos de golpes de arco: martellé e staccato"(IBDEM)

7 "A terceira família, a das arcadas jogadas e saltadas, engloba golpes de arco curtos, separados um do outro por uma pausa, durante a qual o arco (diferentemente das arcadas curtas) abandona a corda, retornando a ela em seguida. Fazem parte desta família dois grupos de golpes de arco: pulados e saltados.(IDEM IBDEM)

8 “A quarta família, como o próprio nome sugere, combina todos os tipos de golpes de arco. 0 número de possibilidades é praticamente ilimitado. Flesch acrescenta que o melhor trabalho conhecido a respeito destas variantes é a School os Bow Technique de Sevcik, compreendendo 4.000 tipos distintos de combinações. (FLESCH, 1962, p.78 apud, SALLES, 1998, p 27). 
sistema pedagógico do violino em quatro capítulos: Técnica e Interpretação, "Mão Esquerda", "Mão Direita" e "Sobre a Prática". Dentro do capítulo Mão direita, encontramos os fundamentos da adaptação dos movimentos naturais do braço, dedos e mão direita para a técnica de arco do violino. Na seqüência, encontramos a sessão "Produção Sonora", a qual será de grande utilidade neste trabalho, pois apresenta similaridades com os três conceitos fundamentais relativos à técnica de arco apresentados por Mello em Articulação do Arco, sessão de seu livro, "Pequena Arte da Expressão".

Galamian enumera estes elementos da sonoridade como: 1 . Velocidade, 2. Pressão, e Ponto Sonoro, ou também chamado, Ponto de Contato (o ponto em que 0 arco se situa sobre as cordas, em relação ao cavalete):

Tendo-se garantido um golpe de arco paralelo ao cavalete, nós devemos considerar esses três fatores fundamentais para a mão direita: (1) a velocidade do golpe de arco, (2) a pressão que ele exerce nas cordas e (3) o ponto em que ele entra em contato com as cordas. Este último se chamará pelo termo "ponto sonoro" ou "sounding point". Esses três fatores são indispensáveis na medida em que uma mudança em qualquer um deles irá requerer uma adaptação correspondente em pelo menos um dos outros. (GALAMIAN, 1903, p 55, tradução nossa)

Estes referenciais teórico-técnicos serão discutidos adiante, ao identificarmos no manual de Mello aspectos sugeridos que se relacionam à execução e aprimoramento destes três fatores aqui levantados.

\section{Pequena Arte da Expressão do Violino}

Mello começa suas instruções precisamente com uma citação de H. Léonard sobre o estudo de um tipo de sonoridade. A frase é de autoria de Viotti: “L'étude des sons filés est un des plus nécessaires de l'art du violon. Viotti l'appelle le travail des mâitres." (MELLO apud LÉONARD, 2003, p.1)

Em sua introdução "Ao leitor", ele afirma que possui leituras sobre os citados "grande mestres":

Reunindo neste pequeno trabalho alguma coisa que de melhor julguei colher na leitura de diversos autores que têm escrito sobre o violino, (instrumento aliás difficil pela incommoda posição a que tanto custa sujeitar-se um principiante), penso no entretanto ter desenvolvido com a devida clareza certos segredos da arte de tocar, tão impossiveis de transmittir-se, quando não se tem a precisa escola para formação do estylo do alumno. (MELLO, 2003, s/ n).

0 autor aqui indica a quem se dirigem seus ensinamentos: “(...) é para o que estuda o violino em algum meio pouco artístico, que escrevi estes apontamentos, a 
fim de que se possa dar alguma orientação ao desenvolvimento da arte de tocar". (MELLO, 2003, p, 3 e 4)

Pelo ambiente realçado na bibliografia consultada, Desterro e São José não eram exatamente centros "pouco artísticos"; todavia, ao falarmos de um ambiente violinístico por 'excelência', não encontramos nenhum dado referente a classes ou conservatórios avançados neste instrumento, tampouco um desenvolvimento do ensino mais aprofundado do violino. Sendo assim, o que concluímos desta dedicatória, é que Adolpho Mello se refere ao ensino artístico do violino num ambiente essencialmente de auto-didatas atentos.

Mello envereda em descrições detalhadas e correções de equívocos sobre o mito maior do violino, arquétipo do virtuose: Paganini`. Sob o olhar analítico de Mello, o mito de Paganini resulta de sua técnica e sua capacidade de expressão, interpretação e composição no estudo de sua mecânica:

Tudo o que Paganini tocava tinha muito vigor e variedade, porque elle sabia regular perfeitamente o arco sobre todos os pontos de sua longitude, conforme o desenvolvimento dos sons conduzidos, na Articulação do ArCo." (MELLO, 2003, p. IV)

Conforme assinalamos, Mello revela-se um músico bem atualizado em relação à música européia e ao conhecimento acadêmico de seu tempo. Ao descrever a técnica de Paganini, ele não apenas toma o grande virtuose como modelo, mas o transforma, em certa medida, em arauto dos conhecimentos que deseja transmitir.

\section{Da 'Articulação do Arco' de Mello em relação à "Produção Sonora' de Galamian}

Mello define o corpo propriamente dito de seu manual ressaltando primeiro o que ele chama de Articulação do Arco. Explica que é da "condução dos sons", ou sua "pronunciação", que resulta a "nuança da expressividade sonora" (a "Pequena Arte da Expressão do Violino" ou "Nuanças que Fazem a Beleza da Execução", como indica o título do trabalho). Dominar a nuança seria então segundo ele, "conduzir os sons a fim de poder graduá-los nas frases, com o recurso de outras nuanças". (MELLO, 2003, p. 1 a 3 ).

9 A escola Italiana chega no seu ápice com Niccolò Paganini, figura que arrebatou histéricas audiências pela perfeição técnica e verve ao tocar, e pela intensa projeção de sua personalidade. Sua música usa praticamente todo trabalho técnico em uma grande, virtuosa e freqüentemente inovadora maneira, incluindo glissandos, harmônicos de todos os tipos, pizzicatos de ambas mãos esquerda e direita, passagens em oitavas duplas, passagens inteiras na corda $G$, acordes de vária cordas, extensões e contrações da mão(esq.), e o uso de scordatura. Staccato, ricochet e arcos mistos de todos os tipos, estavam também em seu repertório de efeitos. (STOWELL, p. 34) 
Entendemos por isso que ele ser refere aos recursos técnicos de sonoridade decorrentes da utilização do arco para a obtenção de gradações no som: dinâmica (forte, piano, crescendo e diminuendo), caráter expressivo ou timbrístico (expressivo, vivo; calmo, sereno, tranqüilo, escuro, claro), velocidade e pressão do arco), além do que é denominado "ponto de contato", ou o ponto em que se situa 0 arco, entre o cavalete e o espelho, nas cordas. (todos estes influem diretamente na dinâmica, timbre e no caráter expressivo do som).

A "Pequena arte da Expressão do Violino", como o título do manual anuncia, parece delimitar a capacidade de criar tipos de sonoridade diferenciados, através do domínio da "articulação do arco", dependendo do caráter e intenção que o violinista deseja conferir ao som.

Encontramos inúmeros tipos de sonoridade passiveis de serem obtidas pelo arco, que são explorados pelo instrumentista e levados à sua melhor execução através de exercícios que incluem noções de dinâmica (domínio destas pelo mecanismo de pressão e velocidade de arco: mais rápido e com menos pressão gerando som mais forte; mais devagar e com mais pressão, som mais denso e piano, dependo da velocidade e da pressão adquirida); de dinâmica e timbre (ponto de contato em relação ao cavalete: mais perto do cavalete, som mais duro e forte ou ríspido e claro; mais longe, som mais doce e piano ou mais suave ou escuro); e da combinação destes elementos entre si, quais seriam a exploração dos mecanismos fundamentais colocados por Galamian. Estes princípios técnicos são colocados por Mello modestamente como "condução dos sons", na manutenção dos mecanismos citados, utilizando-se a dinâmica como condutora do processo da tríade da "Produção Sonora", através do arco:

Como o forte e o piano sejão as nuanças de onde nasce a expressão, a poesia da execução, conjunctamente com o crescendo e decrescendo, constituindo estes nas notas de valor prolongado outro meio de effeito não menos poderoso, mormente nas phrases ascendentes e descendentes, segue-se que temos cinco maneiras de condusir os sons, (...) a saber: forte, piano, crescendo, decrescendo ou a reunião do crescendo e decrescendo ao mesmo tempo.(MELLO, 2003, p. 3- 4)

No caso da velocidade de arco, podemos associar o seguinte trecho:

Para fazer sentir-se um bom effeito de crescendo n'uma escala um tanto rápida e de muitas notas, é preciso poupar o andamento do arco, de modo a fazer-se no principio da escala certa quantidade de notas, com pouco arco, desenvolvendo-se sua rapidez do meio à sua extremidade. No decrescendo observe-se o principio do crescendo. (MELLO, 2003, p. 5, grifo meu)

Os segundo e terceiro pontos da "Produção Sonora" de Galamian, quais são o domínio e controle do arco em relação ao cavalete (ponto de contato) e as variações de pressão do arco, são sugeridos no trecho a seguir: 
Conduzir os sons é augmentar, diminuir ou conservar a sua igualdade de intensidade forte ou piano, esmerando-se o quanto puder que não se conheça a mudanças de arco na repetição das mesmas notas prolongadas, ou graduá-las também nas phrases ascendentes ou descendentes. Para conseguir-se essa igualdade progressiva dos sons (a gradação), (...) onde está o segredo mechanico da expressão, é preciso que se passe o arco suavemente na corda para regular-se o effeito do crescendo $e$ carregando-o com certa força para o decrescendo; isto é, o arco sob a pressão gradual dos dedos, deve approximar-se do cavallete sem aspereza, diminuindo sua pressão no decrescendo." (MELLO, 2003, p. 4 e 5, grifo meu)

A instrução de A. Mello poderia ser interpretada meramente como uma alusão um tanto bruta a tais processos, esclarecidos 40 anos depois por Galamian, este por sua vez, de uma forma muito mais clara em relação aos fundamentos técnico-mecânicos do tocar violino, com sua definição trina da "Produção Sonora". Porém, dado o ambiente local da época, o provável acesso precário aos livros importados de conhecimento especializado e a relativa escassez de bibliografia específica sobre o violino (mesmo falando nos dias atuais), a instrução de Mello se reveste de um caráter muito mais pioneiro e atento do que tecnicamente inexato, revelando um músico e um didata surpreendentemente atualizado em relação aos conhecimentos violinísticos de seu tempo.

0 que Mello denomina "gradação", "condução", "efeito", e "fraseado", e seu desdobramento sonoro em variedades tais como crescendo e decrescendo e todas as variedades das mesmas, além dos elementos de pressão, velocidade e ponto de contato do arco em relação ao cavalete, é então inferido por nós como uma maneira de nominar os três pontos gerais da chamada "Produção Sonora". Estes conceitos técnicos estão no âmago do ensino do violino até os dias de hoje, e são um dos princípios norteadores de qualquer escola de violino. Praticamente todo violinista e professor conceituado no Brasil ou nos grandes centros musicais internacionais tem seu vínculo com estas grandes escolas. 0 que Mello faz é relatar estes aspectos com uma linguagem um tanto rebuscada e nem sempre muito precisa na utilização de termos técnicos.

Também é interessante notar a importância que Mello atribui aos processos técnicos próprios do arco, tendo em vista que esta atenção específica demora a ser um ponto enfatizado no ensino do violino mesmo nos grandes tratados, os quais sempre aludiram muito mais à técnica de mão esquerda. 0 violinista e professor Paulo Bosísio afirma que "os parâmetros como timbre, dinâmica, fraseado, estilo, assim como todos os recursos expressivos - com exceção do vibrato e glissandos _ dependem basicamente do arco". (Bosísı, 1999, p. 3) 


\section{Das diferentes Melodias em relação às Arcadas de Flesch}

Mello entra no campo do que se denomina 'arcadas', na seção de seu manual intitulada "Da ordem da composição-Execução dos três caracteres da Melodia". Nela, expõe o que, segundo seu ponto de vista, são as três grandes famílias da "melodia": 'Da Melodia Sustentada', 'Da Melodia Destacada' e "Da Melodia Mista".

A história da terminologia da técnica violinística revela que alguns nomes como 'golpe de arco' e 'arcadas' sempre foram insuficientemente definidos e um tanto contraditórios, dependo da escola e da tradução para cada idioma. Salles procura definir os dois termos mais precisamente:

Arcadas. [do it. Arcata] 1. Direção do movimento do arco em relação às cordas. 2. Termo genérico, conjunto de golpes de arco com determinada característica em comum; Golpes de arco. Tipo determinado de acentuação e articulação que produz uma sonoridade específica.(SALLES, 1998, p. 20).

Em relação a este particular, como já explicitamos, Flesch classifica os 'tipos de arcadas', perfazendo quatro grandes famílias: as arcadas longas, as arcadas curtas, as arcadas jogadas e as arcadas mistas." (FLESCH, 2000 apud SALLES, 1998, p. 27). Cada uma destas apresenta uma gama de golpes de arco com características comuns. Nas longas, "detaché, legato e filé; nas curtas martelé e staccato; nas jogadas e saltadas, ricochet, sautillé e staccato preso."

Percebe-se grande semelhança entre tais definições de arcadas e as classificações dos tipos de "melodia" por Mello, apenas faltando correlação com as denominadas arcadas jogadas. A articulação do arco, nas suas diferentes melodias deriva então, segundo Mello, do caráter da composição, de seu andamento e da estética de determinado estilo, certas vezes mais enérgico e curto, outras vezes mais solene e legato. Neste sentido, Mello define a Melodia Sustentada:

Esta execução applica-se exclusivamente aos caracteres simples, natural, indeciso, vago, campestre, religioso, tranqüilo, magestoso ou nobre, que pela commodidade de seu andamento, natureza da melodia e intensidade dos sons, fazem logo comprehender sua verdadeira accentuação, desenvolvendo-se, no entanto, a sua gradação e a vibração razoável dos sons, quando a expressão o exigir. (MELLO, 2003, p. 9)

As outras duas classes de melodias são similarmente descritas nos caráter 'destacado' (articulação enérgica, pontuada, stacato) e mista (trechos em legato e outros articulados por ex.).

Consequentemente, concluímos que o que Mello denomina como melodia um tipo de sonoridade obtida com o arco, que envolve o domínio da articulação dos sons nas frases, de acordo com o caráter, o andamento e o estilo da composição. No violino, estes elementos serão definidos através dos diferentes tipos de 'arcadas'. As arcadas englobam por si, os "conjuntos de golpes de arco com determinada 
característica em comum"(SALLES, 1998, p. 20). Mello irá definir 'arcada' logo adiante na parte intitulada $\mathrm{Da}$ Prosódia, porém fica evidente a semelhança entre os pontos ressaltados por Mello para se referir às sonoridades obtidas através do arco e a classificação de arcadas segundo Flesch (2000).

Logo após as diferentes Melodias, ou 'sonoridades', Mello passa a tratar de um novo elemento: Da Pontuação. Aqui se confirma o conceito de articulação pelo arco, através das combinações de notas pontuadas e curtas e suas pausas necessárias. Neste ponto, Mello aproveita para introduzir uma maneira de realizar essas figuras, de colcheias pontuadas e semicolcheias, utilizando o já citado virtuoso e pedagogo de Bériot:

Há pausas de tão curta duração em certos trechos que se excecuta, isto é, uma pontuação tão delicada, tão poética, que não tem nenhuma indicação nas melodias onde se achão incluídas Mas esta pontuação pode achar-se como este princípio: "É nas colcheias pontuadas seguidas de suas semi-colcheias onde existe esta pontuação." (MELLO apud de BERIOT, 2003, p.12).

Encontra-se aí um tipo de técnica conhecida pelos violinistas para resolver estas figuras pontuadas que dispensam certo trabalho, em passagens rápidas, pois possuem um movimento desigual e desproporcional do arco, entre a colcheia pontuada e a semi-colcheia, que é puxada num ataque mais rápido que a sua anterior, impossibilitando a recuperação do arco que foi gasto, tornando desigual os movimento cima-baixo do golpe de arco e muitas vezes atrasando ou adiantando o tempo real das semicolcheias. A pausa citada confere maior clareza de ritmo e articulação a estas figuras pontuadas, e uma economia do movimento do arco na nota mais longa, uniformizando 0 ataque.

No item Da Prosódia (e do Glissando), Mello se refira especificamente às ditas arcadas, ou a "maneira de exprimir a melodia com a sua devida accentuação, isto é, as arcadas." (MELLO, 2003, p. 15) e faz então o exercício de juntar os conceitos apresentados até agora:

É pois, a Prosódia, o grão de força necessária que vem de suas arcadas, que dá vida a poética Pontuação, que origina a expressão da Articulação do Arco, fasendo sobresahir as apojecturas e variando tão abundantemente a execução-Dos diversos golpes de arco destacado. (MELLO, 2003, p 16)

Revisando a análise teórico-técnica feita até agora, entendemos que Mello encadeia estes conceitos técnicos do seguinte modo: a articulação gradual e sutil ou a articulação do som através do arco se constroem com elaboração e exercícios de dinâmica através dos mecanismos de velocidade, pressão e ponto de contato (Galamian), em favor da intenção de construir diferentes sonoridades, estabelecidas pelo caráter, andamento e estilo da composição. 0 termo 'articulação do arco' se refere aos processos mecânicos de gradação ou articulação dos sons, nas suas di- 
ferentes arcadas ou sonoridades, ou as chamadas diferentes melodias, estas que, por sua vez, vão gerar os diferentes golpes de arco.

\section{Considerações Finais}

0 estudo da obra musical e teórica de A. Mello foi e está sendo realizado no intuito de identificar, mapear e difundir a figura do músico, do didata, sua atuação na sociedade de seu tempo, sua obra teórica sobre o violino e o nível de conhecimento específico sobre este instrumento que este músico nos legou. Como mostram seus escritos, Mello conhecia o trabalho de de Bériot e seu antecessor Viotti, e inclusive alguns de seus sucessores ou "pupilos", como H. Léonard, J. Delphin Allard e G. B. Viotti. Evidenciou-se, na análise teórico-técnica de seu manual, princípios da técnica de arco que se viriam a ser norteadores da prática e ensino do violino apenas no século XX, através de contemporâneos seus da Europa, como Flesch e de Bériot, e mesmo quase 50 anos depois do período em que viveu, com Galamian. Os aspectos de Produção Sonora (velocidade, pressão e ponto de contato) e tipos de arcadas (curtas, longas mistas e jogadas), atualmente utilizados como fundamentos na técnica de arco, foram identificados no manual de Mello, de forma pouco explicada, porém inegavelmente pioneira e atenciosa, frente ao contexto em que vivia, as possibilidades de acesso ao material pedagógico e à escassez de bibliografia específica constatada até os dias de hoje. Adolpho Mello mostra-se então em compasso com as atividades musicais de seus contemporâneos e da sociedade na qual atuava. 


\section{Referências Bibliográficas}

> ANDRADA, Laércio Caldeira de. Adolpho Mello. Ext. Anuário Catarinense, Florianópolis, 1955.

> BACHMANN, Alberto Abraham, An encyclopedia of the violin, Da Capo Press, New York, 1966.

> Bosísıo, Paulo Gustavo; LAVIGNE, Marco Antônio. Técnicas Fundamentais de Arco Para Violino e Viola. Departamento de Piano e Instrumento de Cordas do Instituto Villa-Lobos, UNI-RIO, Rio de Janeiro, 1999.

> BRAGA, Ana de Ribamar Goulart. Levantamento de Aspectos da cultura Musical em Desterro, século XVIII e XIX. Dissertação. Florianópolis: Centro de Artes, Universidade do Estado de Santa Catarina, 2000

> CABRAL, Oswaldo Rodrigues. A Música em Santa Catarina no Século XIX.

> Florianópolis: Instituto Histórico e Geográfico de Santa Catarina, 1951.

> FLESCH, CARL. The Art of Violin Playing. Book One. Translated and edited by Eric Rosenblith. Foreword by Anne Sophie Mutter. 65 Blecker Street, Copyright Carl Fisher, New York, 2000.

> GALAMIAN, Ivan. Principles of Violin Playing a Teaching. Englewood Cliffs, New Jersey, Prentice Hall, Inc, 1985, 1962

> GERLACH, Gilberto e MACHADO, Osni. Revista São José - Breve

> História da Cidade e seu Teatro, Edição Especial Ind. Gráfica e Editora Canarinho, Janeiro, 1982.

> MELLO, Adolpho. Da Pequena Arte da Expressão do Violino ou Nuanças que fazem a Beleza da Execução. Instituto Histórico e Ceográfico de Santa Catarina, 2003.

> MURICY, Katia. A Razão Cética : Machado de Assis e as Questões de Seu Tempo. SãoPaulo, Companhia das Letras, 1988

> NOVAIS Fernando A.; ALENCASTRO, Luiz Felipe de. História da Vida Privada no Brasil; 2: Império. São Paulo, Companhia das Letras, 1997

> ROSA, Hélio Teixeira da. Dicionário de Música em Santa Catarina. Florianópolis, Editora do Instituto Histórico e Geográfico de Santa Catarina.Coleção Catarinense no 2, 2002, 232 p.

> SALLES, Mariana Isdebski. Arcadas e Golpes de Arco. A questão da técnica Violinísitca no Brasil: proposta de definição e classificação de arcadas e golpes de arco. Brasília, Thesaurus, 1998.

> STOWELL, Robin. The instrument, its technique and its repertory. In: Grove Music Online, p. 1 à 51. Disponível em :http://www.oxfordmusiconline.com/subscriber/ article/grove/music/41161pg1?print=true. Acessado em outubro de 2010. 
Adolpho Mello - De seu Manual: "Pequena Arte da Expressão do Violino" e Considerações sobre a Música de Salão em Desterro e São José

\section{Jornais}

> A PROVÍNCIA. Desterro, 20/06/1882, Anexo 8, ed. No 1

> A RECENERAÇÃO. Desterro, 20/07/1882. Anexo 6, ed. no 55.

$>$ Desterro, 28/11/1886, Anexo 6, Ed. no. 257

$>$ A REPÚBLICA, Desterro, 27/02/1892, Ed. no 667.

> JORNAL DO COMÉRCIO. Desterro, 24/07/1882, Anexo 8, ed. No 18

$>0$ DESPERTADOR. Desterro, 19/07/1882. Anexo 6, ed. No 55.

> O DIA, Florianópolis, 15/11/1904, ed. no 1145.

$>$, Florianópolis 03/02,1903, ed. no 625.

*Desterro, originalmente denominada Ilha de Santa Catarina, antigo nome da capital de SC, Florianópolis era uma vila que se tornou cidade após a Proclamação da República. São José é uma cidade que atualmente faz parte da região metropolitana de Florianópolis.

Ana Luisa Fridman, cursa o doutorado no Departamento de Música da ECA/USP, sob a orientação do Prof. Rogério Luiz Moraes Costa.

tempoqueleva@yahoo.com.br 